\title{
Kavun bitkisinde (Cucumis melo L.) bulunan Aphis gossypii Glover, 1877 (Hemiptera: Aphididae)'nin popülasyon yoğunluğunun belirlenmesi*
}

\author{
İsmail ALASERHAT ${ }^{1}$, Adnan CANBAY ${ }^{2}$, Özkan BOZBEK ${ }^{1}$, Işıl ÖZDEMİR ${ }^{3}$ \\ ${ }^{1}$ Bahçe Kültürleri Araştırma Enstitüsü Müdürlügü, 24060, ERZINCAN \\ ${ }^{2}$ Kayısı Araştırma Enstitüsü Müdürlüğü, 44090, MALATYA \\ 3Zirai Mücadele Merkez Araştırma Enstitüsü Müdürlügü, 06172, ANKARA
}

*Bu çalışma Tarımsal Araştırmalar ve Politikalar Genel Müdürlüğü [(T.C. Gıda Tarım ve Hayvancılık Bakanlı̆̆ı, Ankara) (TAGEM-BS13/09-01/01-06)] tarafından desteklenmiștir.

Alınıș tarihi: 20 Temmuz 2018, Kabul tarihi: 1 Ekim 2018

Sorumlu yazar: İsmail ALASERHAT, e-posta:i_alaserhat36@hotmail.com

$\ddot{0} \mathbf{z}$

Bu çalışma, 2014-2016 yıllarında Erzincan iline bağlı Merkez ve Üzümlü ilçeleri, bu ilçelere bağlı kasaba ve köylerde açık alanda yetiştiriciliği yapılan kavun bitkisinde yoğun olarak bulunan yaprakbiti türü olan Aphis gossypii Glover, 1877 (Hemiptera: Aphididae)'nin popülasyon yoğunluğunu belirlemek amacıyla yapılmıştır. Bu amaçla Erzincan ili Merkez ve Üzümlü ilçelerinde kavun bitkisi yetiştirilen birer tarlada, fide döneminden hasat döneminin sonuna kadar olan dönemde haftada bir kez örnekleme yapılmıştır. Tarlanın değişik yerlerinden tesadüfen 20 bitki seçilmiş; bitkilerin alt, orta ve üst kısımlarından birer yaprak olmak üzere toplam 60 yaprak alınarak laboratuvara getirilmiş ve laboratuvarda stereo mikroskop altında ergin ve ergin öncesi dönemlerinin sayımları gerçekleștirilmiştir. Böylece yaprak başına düşen yaprakbiti sayısı belirlenmiştir. Çalışma sonucunda A. gossypii'nin kavun bitkisi üzerinde ilk olarak 24.06.2015 (0.1 adet/yaprak) ve 08.06.2016 (0.23 adet/yaprak) tarihleri arasında görüldüğü belirlenmiştir. Ayrıca A. gossypii popülasyonun 03.09.2015 (6.27 adet/yaprak) ve 13.07.2016 (22.5 adet/yaprak) arasında pik yaptığı da tespit edilmiştir.

Anahtar kelimeler: Pamuk yaprak biti, popülasyon yoğunluğu, kavun, Erzincan
Determination of the population intensity of Aphis gossypii Glover, 1877 (Hemiptera: Aphididae) in melon plants (Cucumis melo L.)

\begin{abstract}
This study was conducted to determine population intensity of Aphis gossypii Glover, 1877 (Hemiptera: Aphididae) which is found extensively on melon plants grown outdoors in Erzincan province; Central and Üzümlü districts and towns and villages connected to these districts in 2014-2016. For this purpose, sampling was done in the fields where the melon plant is grown in the Central and Üzümlü districts from seedling period until end of harvesting time once a week. Tree leaf which were one leaf of the lower, middle and upper parts of 20 plants picked from different places of field totally 60 leaves was brought to laboratory and adult and pre-adult periods was recorded by being counted under stereo microscope. Thus, the number of aphids per leaf was detected. It was found that $A$. gossypii was first seen on the melon plant between dates of 24.06.2015 $(0.1$ pieces/leaf) and 08.06.2016 (0.23 pieces/leaf). It was also found that the population of $A$. gossypii peaked between 03.09 .2015 (6.27 pieces/leaf) and 13.07.2016 (22.5 pieces/leaf).
\end{abstract}

Key words: Cotton aphid, population intensity, melon, Erzincan 


\section{Giriş}

Sağlıklı ve dengeli beslenebilmek için insanların ihtiyaç duydukları besin gruplarından biri de sebze ve meyvelerdir. Sebzeler; vitamin ve mineral içerikleri bakımından insan beslenmesinde önemli bir yer tutmaktadır. Kavun kokusu ve tadı hoş, aynı zamanda sağlık açısından da birçok faydası olan sebze türüdür. İçeriğinde bulunan yüksek derecedeki vitamin ve besinler sağlıklı bir yaşam için katkı sağlar. A, B ve $C$ vitaminleri açısından çok zengin olan kavun bitkisi E ve $\mathrm{K}$ vitaminlerini de içerir. Ayrıca sodyum, potasyum, magnezyum, demir, bakır ve alfa-beta karotenleri açısından da yüksek bir içeriğe sahiptir (Anonim, 2018a).

Ülkemizde yetiştirilen kavunların toplam üretim miktarı 1.813.422 ton olup bunun 34.914 tonu Kuzeydoğu Anadolu Bölgesinde, 3860 tonu ise çalışmanın yapıldığı Erzincan ilinde üretilmektedir. Erzincan'daki bu üretim miktarı her ne kadar düşük görünse de (\%11.06) içerisinde yer aldığı Kuzeydoğu Anadolu Bölgesi Iğdır ilinden sonra en yüksek kavun üretiminin gerçekleştirildiği ildir. Ayrıca Erzincan ilinde kavun ekiliş alanı toplamı 1238 da'dır. Bu ekiliş alanın 1039 da'ı (\%83.93) Erzincan ili Merkez ve Üzümlü ilçelerine aittir (Anonim 2017).

Kavun üretimini olumsuz yönde etkileyen birçok zararlı mevcuttur. Bunlardan bazıları karpuz telliböceği [(Henosepilachna elaterii) (Rossi)], kavun kızılböceği [(Rhaphidopalpa foveicollis) (Lucas)], kavun sineği [(Myiopardalis pardalina) (Bigot)], kırmızı örümcekler [(Tetranychus urticae (Koch), T. cinnabarinus (Boisduval), T. atlanticus (McGregor)], pamuk yaprakkurdu [(Spodoptera littoralis) (Boisduval)], tripsler [tütün tripsi (Thrips tabaci) (Lindeman), çiçek tripsi (Frankliniella occidentalis) (Pergande)] ve yaprakbitleri [pamuk yaprakbiti (Aphis gossypii) Glover, bakla yaprakbiti (Aphis fabae) (Scopoli), şeftali yaprakbiti (Myzus persicae) (Sulzer)]'dir (Anonim 2018b). Bu zararlılardan en önemlilerinden biri de yaprakbitleridir. Dünya üzerinde 510 cinse ait toplam 5000 civarında yaprakbiti türü tanımlanmıştır (Blackman and Eastop 2018). Aphis fabae (Scopoli), A. gossypii Glover, Aulacorthum magnoliae (Essig \& Kuwana), A. solani (Kaltenbach) ve Myzus persicae (Sulzer)'nin kavunlar üzerinde (Cucumis melo L.) beslenen yaprakbiti türleri olduğu ifade edilmiștir (Holman 2009). Bu türlerden olan A. gossypii Glover'nin konukçuları arasında kavun bitkisinin de içerisinde yer aldığı Cucurbitaceae familyası bitkileri, turunçgil, pamuk, bamya, susam, fasulye, şekerpancarı, ıspanak, patlıcan, yer fistığı, muz ve nar gibi birçok bitki yer almaktadır. Sebzelerdeki yaprakbitlerinde EZE (ekonomik zarar eşiği); baklagillerde 2550; patlıcan, kabakgil ve lahana gibi büyük yapraklı bitkilerde 20-40 adet yaprakta lupla yapılan sayımlar sonucunda; bir yaprağa düșen zararlı sayısı 10-20 adet olarak belirtilmekte olup, yaprak başına düşen yaprakbiti sayısı bu ve bunun üzerindeki rakamlara çıkınca mücadeleye başlamak gerektiği belirtilmiștir (Anonim 2008). Ülkemizde kavun bitkisi üzerinde bulunan yaprakbitleri üzerine birçok çalışma yürütülmüş olmasına rağmen, Erzincan ilinde şu ana kadar böyle bir çalışma yürütülmemiştir. Bu çalışmada kavun bitkisi üzerinde baskın ve yoğun tür olarak karşımıza çıkan A. gossypii'nin sezon içerisindeki popülasyon gelişimi izlenmiștir.

\section{Materyal ve Yöntem \\ Materyal}

Erzincan ili Merkez ve Üzümlü ilçesine bağlı belde ve köylerde yetiştirilen kavun bitkisi, bu bitkilerle beslenen yaprakbitleri çalışmanın ana materyalini oluşturmuştur. Ayrıca yaprakbitlerinin sayımında kullanılan stereo mikroskop vb. malzemeler çalışmanın diğer materyallerini oluşturmuştur.

\section{Yöntem}

\section{Arazi çalışmaları}

Yaprakbiti türlerinin belirlenmesi amacıyla 2014 yılında Erzincan iline bağlı Merkez ve Üzümlü ilçeleri ile bu ilçelere bağlı kasaba ve köylerde, kavun bitkisinin yetiştirildiği tarlalarda, fide döneminden hasat döneminin sonuna kadar olan dönemde iki haftada bir kez örnekleme yapılmıştır. Kavun bitkisi üzerinde beslenen, koloni oluşturan ve nesil veren yaprakbiti örnekleri, yumuşak bir fırça (samur) ile bitki üzerinden alınıp içerisinde $\% 70$ etil alkol bulunan ephendorf tüplere konulmuş, kod etiketleri de tüplere yerleștirilmiştir. Daha sonra tüplerde bulunan örnekler teşhis edilmek üzere laboratuvarda bulunan buzdolabında $+4^{\circ} \mathrm{C}$ 'de saklanmıștır. Aphis gossypii'nin popülasyon gelişiminin belirlemek amacı ile 2015-2016 yıllarında Merkez ve Üzümlü ilçelerinde konukçusu olan kavun bitkisinin yetiştirildiği birer tarlada, bitkilerin fide döneminden hasat döneminin sonuna kadar haftada bir kez örnekleme yapılmıştır. Örneklemede, tarlanın değişik yerlerinden (örnekleme yapılan noktalar tarlanın kenarlarına gelmeyecek ve birbirine yakın olmayacak şekilde) tesadüfen 20 bitki seçilmiş; bu bitkilerin alt, orta ve üst kısımlarından birer yaprak olmak üzere toplam 60 yaprak alınmış, önce kâğıt torbaya sonra polietilen torbaya konularak buz kutusu içinde laboratuvara 
getirilmiş ve sayımları gerçekleștirilmiștir (Anonim 2002; Canbay ve ark. 2011).

\section{Laboratuvar çalışmaları}

Laboratuvarda, stereo mikroskop altında A. gossypii'nin ergin ve ergin öncesi dönemlerinin sayımları yapılarak kaydedilmiş ve sayılan her bir yaprakbiti örneğinden teșhiste kullanılmak üzere belli sayıdaki birey sıfır numara firça ile içerisinde \%70 etil alkol bulunan tüplere aktarılmıştır. Bu esnada örneklerin hem kanatlı hem de kanatsız ergin bireyler içermesine dikkat edilmiştir. Örneklerin saklanması ve preparasyonu ise Düzgüneş (1980)'e göre yapılmıştır. Düzgüneş (1980) yöntemine göre lam-lamel arası preparatı yapılan yaprakbitlerinin tanıları Bodenheimer and Swirski (1957), Shaposhnikov (1964), Tuatay and Remaudiere (1964), Blackman and Eastop (1984, 1994, 2000, 2006, 2018)'dan yararlanılarak gerçekleştirilmiştir. Ayrıca çalışma alanlarındaki ortalama sıcaklık, ortalama nem gibi meteorolojik veriler popülasyon sayımlarının yapıldığı kavun tarlalarının çevresinde kurulu bulunan Metos firmasına ait üzerinde sıcaklık ve nem sensörleri bulunan elektronik iklim istasyonundan alınarak kaydedilmiştir.

\section{Bulgular}

Erzincan iline bağlı Merkez ve Üzümlü ilçeleri ile bu ilçelere bağlı kasaba ve köylerde açık alanda yetiştiriciliği yapılan kavun bitkisinde bulunan yaprakbiti türlerinin belirlenmesi amacı ile yapılan arazi çalışmaları sonucunda, çalıșmanın ilk yılı olan 2014 yllında kavun bitkisi üzerinde Aulacorthum solani (Kaltenbach, 1843) ve Aphis gossypii Glover, 1877 olmak üzere 2 tür belirlenmiștir. Bu türlerden $A$. solani sadece Merkeze bağlı Bahçeliköy ve Binkoç (26.08.2014 ve 10.09.2014 tarihinde toplanan yaprakbiti örneklerinden) ile Üzümlü ilçesine bağlı Altıntepe (01.10.2014 tarihinde alınan yaprakbiti örneklerinden) köylerinde toplam 3 lokasyonda çok düşük yoğunlukta olduğu tespit edilmiştir. Vejetasyon süresi boyunca gerçekleştirilen sürveylerde alınan yaprakbiti örneklerinin tamamında (bu üç örnek hariç) $A$. gossypii türü tespit edilmiş olup, kavun tarlalarında $A$. solani'ye göre yaprak ve sürgünlerde daha yüksek yoğunluklar oluşturduğu gözlenmiştir. Bu nedenle kavun bitkisi üzerinde $A$. gossypii (Şekil 1) önemli yaprakbiti türü olarak kaydedilmiş ve bu türün popülasyon yoğunluğu takip edilmiștir. 2015 yll Erzincan ili Merkez ve Üzümlü ilçelerinde, A. gossypii'nin kavun bitkisindeki popülasyon gelişimi Şekil 2 ve 3'te verilmiștir.

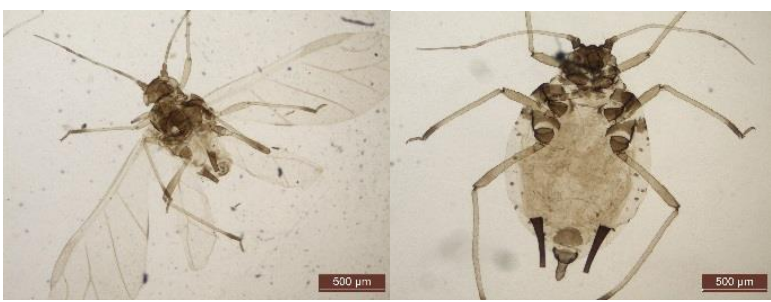

Şekil 1. Aphis gossypii Glover, 1877 a) kanatlı bireyi, b) kanatsız bireyi (Orijinal)

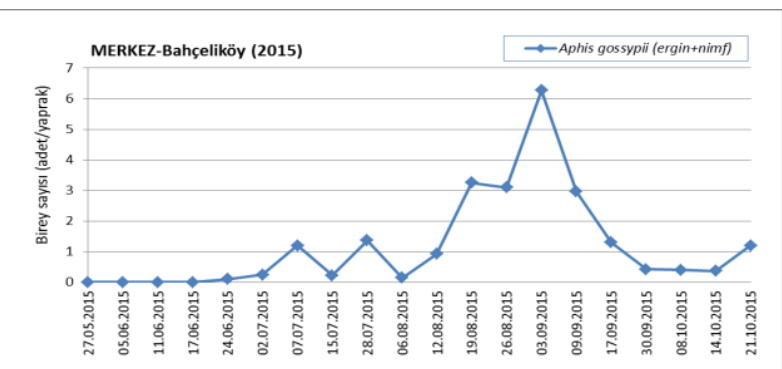

Şekil 2. Merkez Bahçeliköy köyünde Aphis gossypii'nin kavun bitkisindeki 2015 yılı popülasyon gelişimi

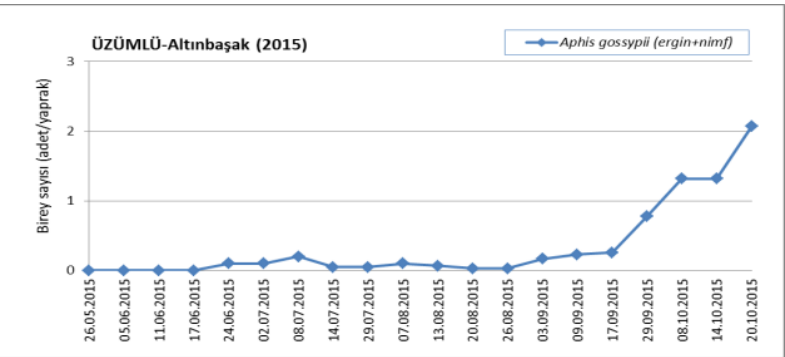

Şekil 3. Üzümlü Altınbaşak beldesinde Aphis gossypii'nin kavun bitkisindeki 2015 yılı popülasyon gelişimi

Merkez Bahçeliköy'deki kavun tarlasında; ilk kez 24 Haziran'da A. gossypii popülasyonu 0.1 adet/yaprak yoğunluğunda görülmeye başlanmış ve 6.27 adet/yaprak ile 03 Eylül'de en yüksek seviyeye erişmiştir. 03 Eylül'den sonra kademeli olarak azalmaya başlayan popülasyon, sezon sonunda 1.2 adet/yaprak ile sona ermiştir (Şekil 2).

Üzümlü Altınbaşak beldesindeki kavun tarlasında; ilk kez 24 Haziran'da $A$. gossypii popülasyonu 0.1 adet/yaprak yoğunluğunda görülmeye başlanmış, 03 Eylül'e kadar düşük seviyede görülen popülasyon, 2.07 adet/yaprak ile en yüksek yoğunluğa vejetasyon periyodu sonu olan 20 Ekim'de erişmiştir (Şekil 3).

Şekil 2 ve 3 incelendiğinde Eylül ayının ilk haftasından itibaren Merkeze bağlı Bahçeliköy'de A. gossypii popülasyonu düşerken Üzümlü ilçesine bağlı Altınbaşak beldesinde popülasyon yükselişe geçmiştir. 
Her iki bölgenin ortalama sıcaklık ve nispi nem değerleri birbirine yakın olmasına rağmen (Şekil 4 ve 5) böyle bir durumun görülmesi ancak şu şekilde açıklanabilinir. Öncelikle Bahçeliköy'deki kavun tarlasında sezon erken bitmiş olup üretici ilk mahsulünü aldıktan sonra gerekli bakım işlemlerini (sulama, gübreleme vs.) yerine getirmezken; Altıbaşak beldesindeki kavun tarlasında üretici sezon boyunca gerekli bakım işlemlerini devam ettirmiştir. Bilindiği üzere yaprakbitleri beslenmek için taze sürgün ve yaprakları tercih ederler. Altınbaşak'taki kavun tarlasında vejetasyon boyunca sürekli taze sürgün ve yaprak olması $A$. gossypii popülasyonunun Eylül ayından sezon sonuna kadar artmasına yol açtı ğ kanaatini taşımaktayız. Çalışmanın gerçekleştirildiği lokasyonlardaki meteorolojik veriler (ortalama sicaklık ve nispi nem değerleri) Şekil 4 ve 5'de verilmiştir.

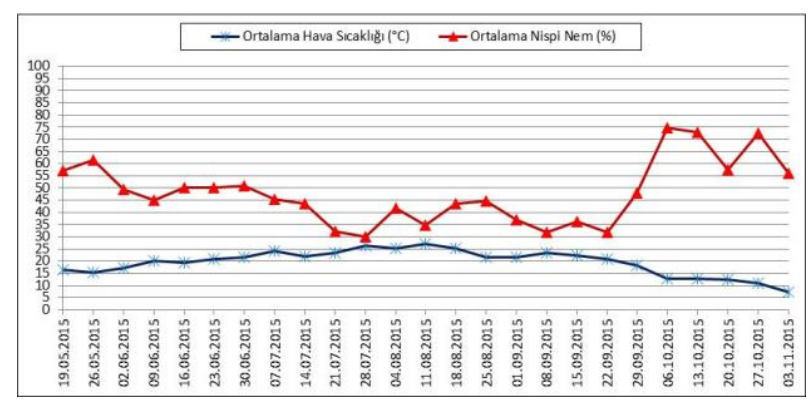

Şekil 4. 2015 yılı (Mayıs-Kasım) Merkez Bahçeliköy köyüne ait haftalık ortalama meteorolojik veriler

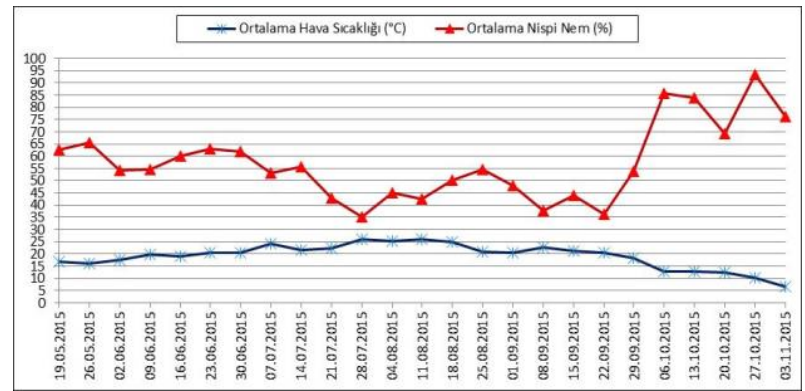

Şekil 5. 2015 yılı (Mayıs-Kasım) Üzümlü Altınbaşak beldesine ait haftalık meteorolojik veriler

Aphis gossypii'nin kavun tarlalarında ilk görüldüğü tarihlerde nem Bahçeliköy'de \%44,5, Altıbaşak'ta $\% 54.9$ ve sıcaklık değerleri ise Bahçeliköy'de $23.7^{\circ} \mathrm{C}$, Altıbaşak'ta ise $23.3^{\circ} \mathrm{C}$ 'dir. Nem değerlerinin Bahçeliköy'de \%25.3, Altıbaşak'ta \%35.8 ve sıcaklık değerlerinin ise Bahçeliköy'de $23^{\circ} \mathrm{C}$, Altıbaşak'ta ise $21.8^{\circ} \mathrm{C}$ olduğu dönemlerde ise popülasyon en yüksek seviyesine ulaşmıştır (Şekil 4-5). 2016 yılı Erzincan ili Merkez ve Üzümlü ilçelerinde, A. gossypii'nin ka- vun bitkisindeki popülasyon gelişimi ise Şekil 6 ve 7'de verilmiștir.

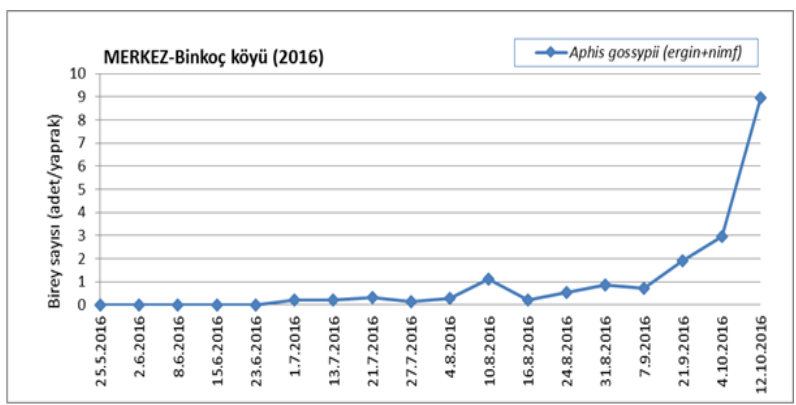

Şekil 6. Merkez Binkoç köyünde Aphis gossypii'nin kavun bitkisindeki 2016 yılı popülasyon gelişimi

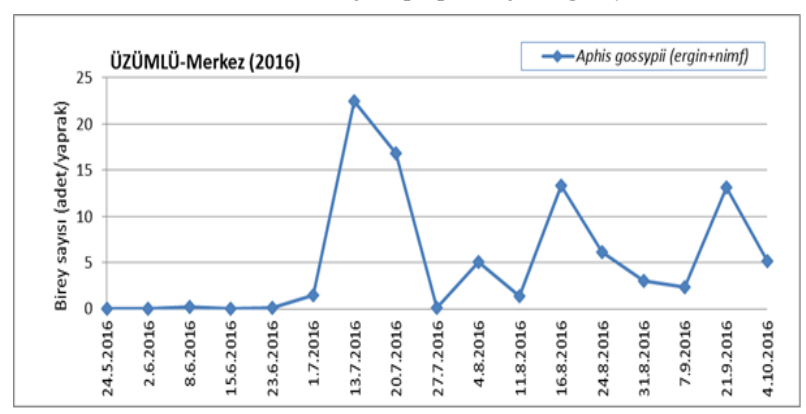

Şekil 7. Üzümlü Merkez'de Aphis gossypii'nin kavun bitkisindeki 2016 yılı popülasyon gelişimi

Merkez Binkoç köyündeki kavun tarlasında; ilk kez 0.2 adet/yaprak yoğunluğunda 1 Temmuz'da görülmeye başlayan A. gossypii popülasyonu, uzun bir süre düşük yoğunlukta devam etmiş ve sezon sonunda (12 Ekim) 8.97 adet/yaprak ile en yüksek seviyeye erişmiştir (Şekil 6). Aphis gossypii popülasyonunun ilk görüldügü tarihte ortalama sicaklık 21.5 ${ }^{0} \mathrm{C}$, orantılı nem \%54.2; maksimum seviyeye ulaştığı tarihte ortalama sıcaklık $12.8^{\circ} \mathrm{C}$, orantılı nem \%62.9 olarak belirlenmiştir (Şekil 8).

Üzümlü Merkez'deki kavun tarlasında; A. gossypii popülasyonu 0.23 adet/yaprak yoğunluğunda ilk kez 8 Haziran'da görülmeye başlamış, bir süre düşük seviyede devam eden popülasyon 22.5 adet/yaprak ile 13 Temmuz'da en yüksek yoğunluğa ulaşmıştır. Yaprakbitine karşı yapılan ilaçlama ile seviyesi düşen yaprakbiti popülasyonu, Temmuz ayının son haftasından sonra dalgalı bir seyir izleyerek ekonomik zarar eşiğini (20 adet/yaprak) aşmayan küçük tepe noktaları oluşturmuştur (Şekil 7). A. gossypii popülasyonunun ilk görüldüğü tarihte ortalama sicaklık $12.8^{\circ} \mathrm{C}$, orantılı nem $\% 91.1$; maksimum olduğu tarihte ortalama sıcaklık $23.2^{\circ} \mathrm{C}$, orantılı nem $\% 47.5$ oranında olmuştur (Şekil 9). 


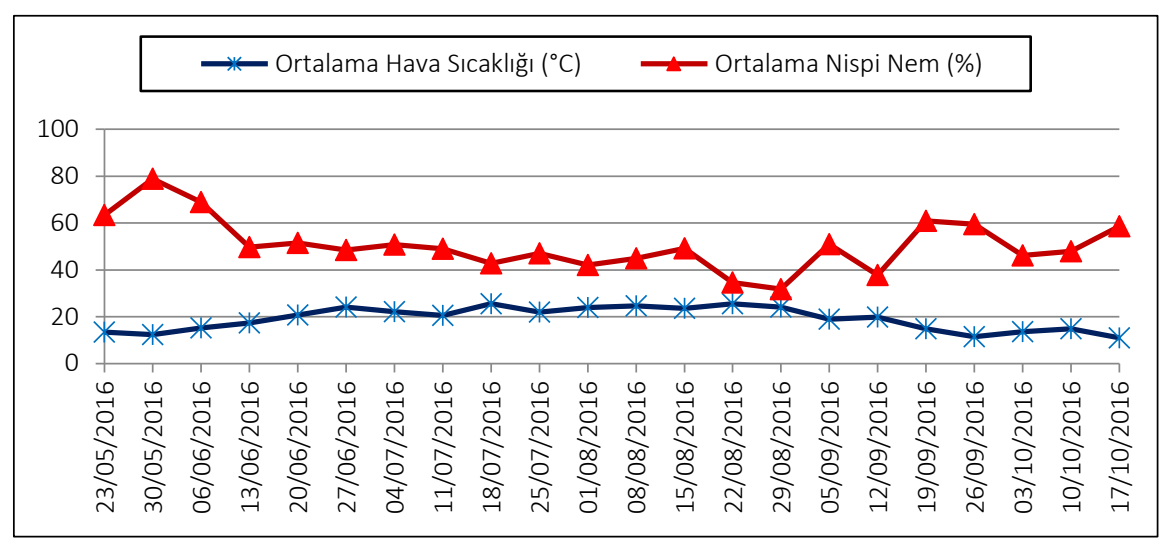

Şekil 8. 2016 yılı (Mayıs-Ekim) Merkez Binkoç köyüne ait haftalık meteorolojik veriler

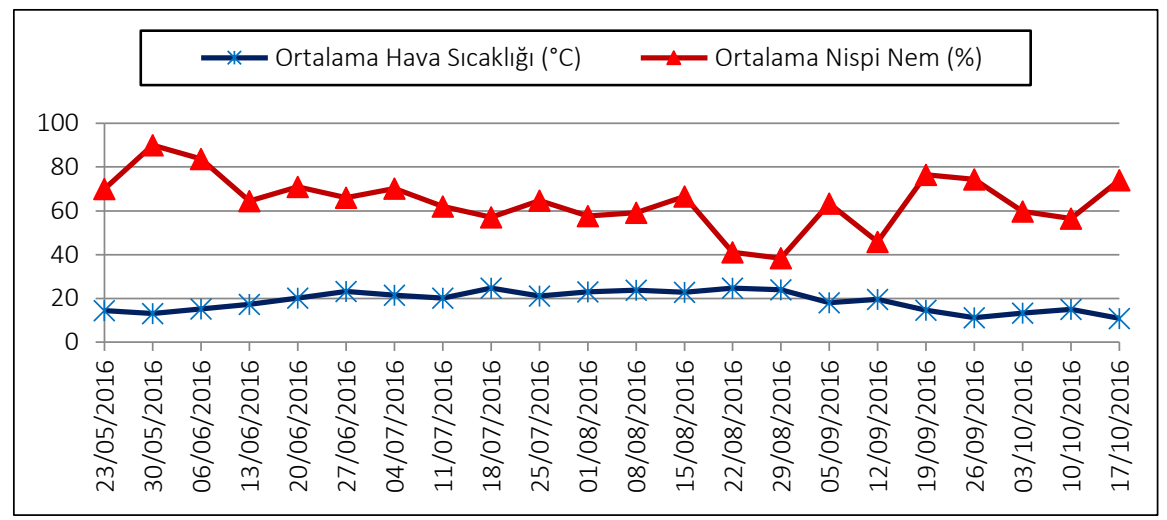

Şekil 9. 2016 yılı (Mayıs-Ekim) Üzümlü merkeze ait haftalık meteorolojik veriler

\section{Sonuçlar ve Tartışma}

Çalışma sonucunda önemli tür olarak belirlenen $A$. gossypii'nin kavun bitkisi üzerinde ilk görüldügü tarihlerde (24.06.2015-08.06.2016) sicaklık değerleri sırası ile $20.4-12.8^{\circ} \mathrm{C}$ ve nem değerleri ise \%50.191.1 arasında iken popülasyonun pik yaptığ tarihlerde (03.09.2015-13.07.2016) sicaklık değerleri ise $21.57-23.2^{\circ} \mathrm{C}$ ve nem değerleri ise $\% 36.9-47.5$ arasinda seyretmiștir. Kavun bitkisi üzerinde bulunan $A$. gossypii'nin doğada $12.8-23.2^{\circ} \mathrm{C}$ sıcaklık ve \%36.991.1 nem değerlerinde bulunduğu, çalışma sonucunda tespit edilmiştir. Bayram (2013), tarafından Diyarbakır'da yapılan çalışmada $A$. gossypii'nin kanatsız formlarının farklı karpuz çeşitleri üzerinde ilk kez 3-10 Haziran'da görüldüğü, 15-22 Haziran'da popülasyonun ilk pik noktasını, 7 Eylül'de ise ikinci pik noktasını oluşturduğu belirtilmiştir. A. gossypii'nin farklı karpuz çeşitleri üzerinde kanatlı formlarının ise ilk kez 25-27 Mayıs'ta görüldüğü, 21-28 Eylül'de popülasyonun ilk pik noktasını, 12-19 Ekim'de ise ikinci pik noktasını oluşturduğu tespit edilmiștir. Bu çalışma Diyarbakır ilinde yürütüldüğünden vejetasyona bağlı olarak $A$. gossypii'nin doğada ilk görülme tarihleri ve ilk pik noktaları bizim çalışmamıza göre yaklaşı 20 gün daha erken seyretmektedir. Ancak sezon sonuna doğru bizim çalışmamıza paralel olarak $A$. gossypii popülasyonunun pik yaptığı görülmektedir. Karley et al. (2004), llıman iklim bölgelerindeki yaprakbiti populasyonlarının yaz ortasından hemen sonra birkaç gün içinde en üst seviyeden anormal bir düşusşe geçtiğini, 6-8 hafta sonra popülasyonun tekrar arttığını belirterek, yaz ortasındaki bu ani düşüşün bitki besin kalitesindeki azalma ve sezon boyunca doğal düşman baskısının artmasından kaynaklandığını söylemektedir. Sağanak yağmur gibi hava olaylarının da populasyon azalmasına neden olabileceğini belirtmekle birlikte bu gibi ekstrem durumların ani popülasyon düşmesine her zaman yardımcı olamayacağını bildirmektedirler. Yapmış olduğumuz bu çalışmada A. gossypii popülasyonu genel itibarı ile temmuz ayının ilk haftasından itibaren yükselişe geçmiş olsa da bu haftadan sonra popülasyon tekrar düşüşe geçmiş ve dalgalı bir seyir izlemiștir. A. gossypii popülasyonundaki bu düşüşün; yükselen sıcaklık, doğal düşman popülasyonunun artmasına bağlı olarak oluşan doğal düşman baskısı, bu dönemlerde görülen sağanak yağmur vb. nedenlerden kaynaklandığını tahmin etmekteyiz. Vuonga et al. (2001), Kore'nin Chinju Bölgesi'nde Myzus per- 
sicae (Sulz.) ve A. gossypii'nin seralarda geniş ölçüde tarımı yapılan beş kültür bitkisinde yaygınlık gösterdiği; domates, patates ve Çin kabağı bitkilerinde $M$. persicae'nin, karpuz ve biberde ise $A$. gossypii'nin yoğun olarak bulunduğu, her iki yaprakbitinin en yüksek popülasyon seviyelerine, haziran ayı ortalarında muson yağmurlarının henüz başlamadığı ve sıcaklığın $23^{\circ} \mathrm{C}$ civarında olduğu dönemde ulaştığ bildirilmiştir.

$\mathrm{Bu}$ çalışmayla Erzincan ilinde yetiştiriciliği yapılan kavun bitkisinde bulunan önemli yaprakbiti türü olan A. gossypii belirlenerek, bu türün popülasyon değişimleri ile zararlının doğada ilk çıkıș tarihleri ve pik yaptığı tarihler belirlenmiş, bu tarihlerdeki sıcaklık ve nem değerleri ile popülasyon yoğunluğu arasındaki ilişkileri tespit edilmiştir. Böylece $A$. gossypii'nin kavun agro-ekosistemindeki durumları ile ilgili önemli bilgiler sağlanmıştır.

\section{Teşekkürler}

$\mathrm{Bu}$ çalışma Tarımsal Araştırmalar ve Politikalar Genel Müdürlüğü tarafından (TAGEM-BS-13/0901/01-06) desteklenmiştir. Ayrıca Erzincan Bahçe Kültürleri Araştırma Enstitüsü'nün laboratuvar imkânlarından faydalanılmıștır. Desteklerinden dolayı Tarımsal Araştırmalar ve Politikalar Genel Müdürlüğü'ne ve Erzincan Bahçe Kültürleri Araştırma Enstitüsü'ne teșekkür ederiz.

\section{Kaynaklar}

Anonim 2002. Örtüaltı Sebze Yetiștiriciliğinde Entegre Mücadele Teknik Talimatı. Tarım ve Ormancılık Bakanlığı, Tarımsal Araştırmalar ve Politikalar Genel Müdürlüğü Yayınları, Ankara, $141 \mathrm{~s}$.

Anonim 2008. Zirai Mücadele Teknik Talimatları. Gıda, Tarım ve Hayvancılık Bakanlı̆̆ı, Tarımsal Araștırmalar ve Politikalar Genel Müdürlüğü Yayınları, Ankara, Cilt 3: 322 s.

Anonim 2017. Bitkisel Üretim İstatistikleri. T.C. Başbakanlı Devlet İstatistik Enstitüsü, https://biruni.tuik.gov.tr

Anonim 2018a. Kavunun faydaları. https://www.faydalarizararlari.com/kavununfaydalari/ (Erișim tarihi: 28.03.2018).

Anonim 2018b. Kavun karpuz hastalık ve zararlıları ile mücadele. https://www.tarim.gov.tr (Erişim tarihi: 25.06.2018).

Bayram, Y., 2013. Pamuk Yaprakbiti, Aphis gossypii Glover (Hemiptera: Aphididae)'nin Farklı Karpuz Çeşitlerinde Bazı Biyolojik Parametreleri, Popülasyon Dalgalanması, Doğal Düşmanların Tespiti ve Etkin- liklerinin Belirlenmesi. Dicle Üniv. Fen Bilimleri Ens., Doktora Tezi, Diyarbakır, 95 s.

Blackman, R.L., Eastop, V.F., 1984. Aphids on the World's Crops: An Identification Guide. A Wiley. Intenscience Publication, $466 \mathrm{p}$.

Blackman, R.L., Eastop, V.F., 1994. Aphids on the World's Trees: An Identification and Information Guide. CAB International. Department of Entomology the Natural History Museum, London, England, 986+16

Blackman, R.L., Eastop, V.F., 2000. Aphids on The World's Crops: An Identification Guide. Second Edition. A Wiley. The Natural History Museum Intenscience Publication, London, England, 414 p.

Blackman, R.L., Eastop, V. F., 2006. Aphids of the World's Herbaceous Plants and Shrubs; An Identification and Information Guide, John Wiley, USA, $1439 \mathrm{p}$.

Blackman, R.L., Eastop, V.F., 2018. Aphids of the world's plants; an online identification and information guide. http://www.aphidsonworldsplants.info/ Introduction.htm (Access date 28.03.2018).

Bodenheimer, F.S., Swirski, E., 1957. The Aphidodea of the Middle East. The Weizmann Science Press of Israel, Jerusalem, Israel, $378 \mathrm{p}$.

Canbay, A., Bozbek, Ö., Alıcı, H., Çakırbay, İ.F., 2011. Erzincan ili örtüaltında yetiştirilen domates ve hıyarlarda görülen zararlı türlerin tespiti ve popülasyon gelișimi. Bitki Koruma Bülteni, 51 (2): 119-146.

Düzgüneş, Z., 1980. Küçük Arthropodların Toplanması, Saklanması ve Mikroskobik Preparatların Hazırlanması. T.C. Gıda-Tarım ve Hayvancılık Bakanlığı, Zirai Mücadele ve Zirai Karantina Genel Müdürlüğü, Ankara, $77 \mathrm{~s}$.

Holman, J., 2009. Host Plant Catalog of Aphids Palaearctic Region. Academy of Sciences of the Czech Republic Press, Branišovská, 1215 p.

Karley, A.J., Parker, W.E., Pitcford, J.W., Douglas, A.E., 2004. The mid-season crash in aphid populations: Why and how does it occur? Ecological Entomological, 29: 383-388.

Shaposhnikov, G.K., 1964. Suborder Aphidinea-Plant lice. (In Keys to the Insects of the European Part on the USSR. Editör: G. Bei-Bienko. 616-799 pp.

Tuatay, N., Remaudiere, G., 1964. Premiere contribution au catalogue des Aphididae (Hemiptera) de la Turquie. Rev. Path. Vegveale et D'entomologie Agricole de France, 43 (4): 243-278.

Vuonga P.T., Kimb, J., Songb, Y., 2001. The seasonal occurrence of the two aphid species, Myzus persicae and Aphis gossypii, and their natural enemies on vegetable crops in Chinju, Korea. Journal of Asia-Pacific Entomology, 4 (1): 41-44. 